\title{
The Polish MacNew heart disease heath-related quality of life questionnaire: A validation study
}

\author{
Joanna M. Moryśs ${ }^{1,2}$, Stefan Höfer ${ }^{3}$, Andrzej Rynkiewicz ${ }^{4}$, Neil Bryan Oldridge ${ }^{5,6}$ \\ ${ }^{1}$ Department of Clinical Psychology, Medical University of Gdansk, Gdansk, Poland \\ ${ }^{2} 1^{\text {st }}$ Cardiology Clinic, Medical University of Gdansk, Gdansk, Poland \\ ${ }^{3}$ Department of Medical Psychology, Innsbruck Medical University, Innsbruck, Austria \\ ${ }^{4}$ Department of Cardiology and Cardiosurgery, Division of Cardiology and Internal Diseases, \\ Warmia and Mazury, Olsztyn, Poland \\ ${ }^{5}$ School of Medicine and Public Health, University of Wisconsin, Wisconsin, United States \\ ${ }^{6}$ Aurora Cardiovascular Services, Aurora Medical Center, Milwaukee, Wisconsin, United States
}

\begin{abstract}
Background: The MacNew health-related quality of life questionnaire was designed to assess feelings about how heart disease affects their daily physical, emotional and social functioning in patients with 1 of the 3 major coronary artery diagnoses, stable coronary artery disease (CAD) with angina, ST-elevation myocardial infarction (STEMI), and ischemic heart failure (HF). The aim of this study was to determine the reliability and validity of the Polish version of the MacNew in patients with CAD.
\end{abstract}

Methods: Patients with CAD completed a self-report sociodemographic and clinical questionnaire: the MacNew, the Short-Form 36 Health Survey, and HADS at baseline; $10 \%$ of the patients completed each questionnaire 2 weeks later.

Results: We studied patients with stable CAD with angina $(n=115)$, with STEMI $(n=112)$, and with ischemic HF $(n=105)$. Internal consistency reliability was demonstrated with Cronbach's a from 0.86 to 0.95 for the MacNew global scale and subscales. The original 3-factor structure was confirmed for the Polish version of the MacNew explaining 53.5\% of the variance. Convergent validity of similar MacNew and SF-36 subscales was confirmed in the total group and in each diagnosis. Discriminant validity with the SF-36 health transition was fully confirmed in the total group and in patients with HF and partially confirmed in patients with stable CAD with angina or myocardial infarction.

Conclusions: The Polish MacNew health-related quality of life questionnaire can be recommended in patients with stable CAD with angina, myocardial infarction and HF. (Cardiol J 2015; 22, 5: 541-550)

Key words: MacNew validation, health-related quality of life, coronary artery disease

\section{Introduction}

One of the more important developments in health care in the past decade or two may be the recognition that the patients' perspective is as legitimate and valid as the clinician's in monitor- ing health status and health care outcomes [1-4]. There are several disease-specific health-related quality of life (HRQL) inventories for patients with the 3 major coronary artery disease (CAD) diagnoses - stable $\mathrm{CAD}$ with angina [5], myocardial infarction (MI) [6] and heart failure (HF) [7].

Address for correspondence: Dr Joanna M. Moryś, Department of Clinical Psychology, Medical University of Gdansk, ul. Tuwima 15, 80-210 Gdańsk, Poland, tel: +48 5834917 92, fax: +48 58349 17 92, e-mail: jmmorys@gmail.com 
Disease-specific questionnaires are more relevant and so more sensitive than generic HRQL questionnaires but do not allow between-diagnosis comparisons suggesting the potential need for a single core $\mathrm{CAD}$-specific questionnaire to cover the 3 major CAD diagnoses [8].

The MacNew HRQL questionnaire was designed to assess patients' feelings about how heart disease affects daily functioning and contains 27 items with a global HRQL score and physical limitation, emotional, and social function subscales [6]. As part of the international HeartQoL Project conducted in 22 different countries [9], the MacNew was translated into Polish using forward-backward translation [10]. The MacNew HRQL has been translated also into 38 languages and all translated and validated versions of MacNew can be accessed at MacNew.org [11].

The aim of this study was to determine the reliability and validity of the Polish version of the MacNew in patients with CAD for both researchers and practitioners in Poland to monitor the effectiveness of different treatments or the same treatment in the 3 major CAD diagnoses.

\section{Methods}

\section{Subjects}

A convenience sample of 332 patients with angina $(n=115)$, ST elevation MI (STEMI $(n=112)$, or with ischemic HF $(\mathrm{n}=105)$ was recruited from the Department of Cardiology, Medical University of Gdansk and the 3 cardiac rehabilitation units of the Health Clinic: "Leśnik" and "Helios" in Sopot as well as "Neptun" in Wieżyca. We recruited patients who were being treated for current typical chest pain based on positive non-invasive testing (exercise testing, stress echo, or nuclear imaging) and/or positive invasive testing (coronary angiography); patients with MI were recruited 4 weeks to 6 months after a documented STEMI; and patients with ischemic HF were recruited based on a left ventricular ejection fraction $<40 \%$ (diagnosed on base of echo or left heart catheterization) and angina (documented previous Ml, exercise testing, stress echo. nuclear imaging or angiography). Patients also had to be at least 18 years old, have no major psychiatric disorders, no present substance abuse and were able to complete the Polish-language questionnaires.

The Medical Ethics Committee of the Medical University of Gdansk approved the study protocols. Subjects were given the opportunity to not participate in the study or resign at any stage.

\section{Patients-reported outcome assessment}

A doctor referred patients to the HeartQoL Project and provided the patient's routine diagnostic and clinical data. All patients completed a self-report sociodemographic and clinical questionnaire. The MacNew [6], the Short-Form 36 Health Survey (SF-36) [12], and Hospital Anxiety and Depression Scale (HADS) [13] were completed at baseline by all patients and again 2 weeks later by approximately $10 \%$ of patients for testing instrument test-retest reliability. The questionnaires were completed a few days after admission to the Department of Cardiology or cardiac rehabilitation unit.

\section{MacNew HRQL}

The MacNew questionnaire is a 27 -item selfadministered questionnaire with a global scale and a physical, emotional and social subscale. The MacNew has a 2-week timeframe and is designed to assess patient's feelings about how CAD affects daily functioning with each item scored from 1 (low HRQL) to 7 (high HRQL) [6, 14]. A score is generated for each of the physical, emotional and social MacNew subscales as the mean of the number of subscale items with a response; the MacNew global score is the sum of the score on all scored items divided by the number of scored items. The MacNew was translated into Polish using the linguistic validation forward-backward translation technique [10].

\section{Short Form-36}

The Short-Form SF-36 is a valid health survey consisting of 36 items consisting of two scales, a physical component summary (PCS), and a mental component summary (MCS) [12]. Raw scores are summed and then transformed to a 0-100 scale. The SF-36 questionnaire is widely used in patients with CAD and is available in Polish [15].

\section{Hospital Anxiety and Depression Scale}

The HADS is an extensively used 14-item psychological screening instrument designed to detect symptoms of anxiety and depression [13]. A score of 8 or more indicates symptoms of either depression or anxiety [16] and the Polish version of the HADS has been validated [17].

\section{Statistical analysis}

Patient clinical and sociodemographic characteristics are described as either dichotomous (\%) or continuous variables (mean \pm standard deviation). Analysis of variance (ANOVA) was used to examine differences and change in outcome data. 
Floor and ceiling effects

Floor effects occurred when patients scored at the lowest MacNew HRQL score, i.e., 1, and ceiling effects occurred at the highest HRQL score, i.e., 7. The presence of floor effects indicates instrument sensitivity in detecting worsening health status while ceiling effects indicate sensitivity in detecting significant health improvements [18].

\section{Reliability}

The reliability of the MacNew was evaluated by examining its internal consistency (Cronbach's $\alpha$ ); test-retest reliability (14-day) was assessed in a subsample of approximately $10 \%$ patients with the intraclass correlation coefficient (ICC) where a value of $\geq 0.70$ is considered acceptable for group comparisons [19].

\section{Validity}

To assess convergent validity, we compared the ICC between the corresponding MacNew and SF-36 scales (Pearson ICC $<0.10-$ absent, 0.10-0.30 - weak, 0.30-0.49 - moderate and $\geq 0.50$ - strong) hypothesizing strong correlations between similar constructs, i.e., the SF-36 Health Survey PCS and MCS and the corresponding MacNew scale constructs, and significantly lower correlations between dissimilar constructs [20, 21]. To assess discriminative validity, we used the "known groups" approach [18] hypothesizing that A) patients who report improvement or no change on the SF-36 health transition item would have better HRQL than patients who reported deteriorated health and $\mathrm{B}$ ) and that patients who showed symptoms of anxiety or depression on the HADS (HADS cut-off scores, $\geq 8$ ) would have poorer HRQL than those patients without symptoms of anxiety or depression.

\section{Results}

Sociodemographic and clinical data (Table 1)

Baseline sociodemographic and clinical data were collected in all 332 patients and detailed characteristics are presented in Table 1 . The mean age of all patients was $60.2 \pm 10.1$ years, the majority of patients were men $(74.4 \%)$ and there were no statistically significant differences in the gender distribution between the clinical groups. Patients with HF were approximately 5 years older than patients with MI or angina. Patients with higher education were most likely to be in the angina group while the largest proportion of patients with primary education had HF. Statisti- cally significant differences were observed by education between the groups with HF and MI. Patients with MI were more likely to be smokers than patients with either angina or $\mathrm{HF}(\mathrm{p}=0.012)$. Patients with angina were more likely to report that their doctor told them they had hypertension than patients with MI or HF $(\mathrm{p}<0.01)$ and were more likely to report having hypercholesterolemia than patients with HF $(\mathrm{p}<0.01)$. Patients with angina were more likely to engage in regular physical exercise than patients with either MI or HF $(\mathrm{p}=0.001)$.

Health-related quality of life scores (Table 2)

The mean MacNew scores ranged from 4.5 on the physical subscale, to 4.8 on the global scale, to 4.9 on the social subscale and to 5.0 on the emotional subscale in the total group. Patients with MI had significantly higher scores on the MacNew global scale and each subscale than patients with either angina or HF $(\mathrm{p}<0.001)$.

The mean PCS score was 37.5 with a mean MCS score of 45.8 in the total group. Patients with MI had significantly higher PCS scores than patients with either angina or HF $(p<0.001)$ with no between-diagnosis differences on the MCS.

The mean HADS anxiety score was 7.4 with a mean HADS depression score of 6.1 in the total group. Patients with MI had significantly lower $(\mathrm{p}<0.05)$ HADS anxiety scores than patients with angina and significantly lower $(\mathrm{p}<0.05)$ HADS depression scores than patients with HF.

\section{MacNew questionnaire item characteristics (Table 3)}

There were no MacNew floor effects in the total group or by diagnosis. There were no MacNew ceiling effects in patients with angina; however, ceiling effects occurred in $\leq 1.2 \%$ of the total group, in $\leq 1.8 \%$ of patients with $\mathrm{MI}$ and in $\leq 1.9 \%$ of patients with HF.

\section{Psychometric analysis \\ MacNew reliability (Table 3). Internal consistency reliability. Cronbach's $\alpha$ ranged} from 0.94 (global scale), to 0.91 (physical and emotional subscales), and 0.90 (social subscale) in the total group. By diagnosis, Cronbach's $\alpha$ ranged from a high of 0.92 on the physical subscale in patients with $\mathrm{HF}$ and on emotional subscale in patients with angina to a low of 0.86 on the physical subscale in patients with angina. Test-retest reliability. The 14-day ICCs for global scale and subscales were significant $(\mathrm{p}<0.01)$ in the total 
Table 1. Sociodemographic and clinical characteristics (mean \pm standard deviation; or \%) of the total group of patients and by diagnosis (stable coronary artery disease with angina [Angina], myocardial infarction $[\mathrm{MI}]$ and heart failure $[\mathrm{HF}]$ ); data missing when total $<100 \%$.

\begin{tabular}{|c|c|c|c|c|c|}
\hline $\begin{array}{l}\text { Patient } \\
\text { characteristics }\end{array}$ & $\begin{array}{l}\text { Total group } \\
(\mathrm{n}=332)\end{array}$ & $\begin{array}{c}\text { Angina } \\
(n=115)\end{array}$ & $\begin{array}{c}\text { MI } \\
(n=112)\end{array}$ & $\begin{array}{c}\text { HF } \\
(n=105)\end{array}$ & $\mathbf{P}$ \\
\hline Age [year] & $60.2 \pm 10.1$ & $58.4 \pm 8.6$ & $59.1 \pm 10.4$ & $63.4 \pm 10.5$ & $<0.001^{\mathrm{b}, \mathrm{c}}$ \\
\hline \multicolumn{6}{|l|}{ Gender: } \\
\hline Male & $74.4 \%$ & $71.3 \%$ & $71.4 \%$ & $81.0 \%$ & \multirow[t]{2}{*}{0.20} \\
\hline Female & $25.6 \%$ & $28.7 \%$ & $28.6 \%$ & $19.0 \%$ & \\
\hline \multicolumn{6}{|l|}{ Family status: } \\
\hline Single & $15.4 \%$ & $12.2 \%$ & $17.0 \%$ & $17.1 \%$ & \multirow[t]{3}{*}{0.94} \\
\hline Married & $75.3 \%$ & $82.6 \%$ & $70.5 \%$ & $72.4 \%$ & \\
\hline Other & $9.3 \%$ & $5.2 \%$ & $12.5 \%$ & $10.5 \%$ & \\
\hline \multicolumn{6}{|l|}{ Employment: } \\
\hline White collar & $44.6 \%$ & $49.6 \%$ & $45.5 \%$ & $38.1 \%$ & \multirow[t]{2}{*}{0.22} \\
\hline Blue collar & $55.4 \%$ & $50.4 \%$ & $54.5 \%$ & $61.9 \%$ & \\
\hline \multicolumn{6}{|l|}{ Education: } \\
\hline Primary & $40.7 \%$ & $33.0 \%$ & $39.3 \%$ & $50.5 \%$ & \multirow[t]{3}{*}{$0.04^{b}$} \\
\hline Secondary & $40.1 \%$ & $43.5 \%$ & $43.8 \%$ & $32.4 \%$ & \\
\hline Higher: & $19.3 \%$ & $23.5 \%$ & $17.0 \%$ & $17.1 \%$ & \\
\hline Anxious $[\mathrm{HADS} \geq 8$ ] & $45.2 \%$ & $51.3 \%$ & $57.1 \%$ & $41.0 \%$ & 0.24 \\
\hline Depressed $[\mathrm{HADS} \geq 8]$ & $31.3 \%$ & $33.9 \%$ & $23.2 \%$ & $37.1 \%$ & 0.07 \\
\hline Body mass index & $28.0 \pm 4.4$ & $29.1 \pm 4.1$ & $27.6 \pm 3.9$ & $27.2 \pm 4.9$ & $0.003^{\mathrm{a}}$ \\
\hline Smoker & $25.9 \%$ & $21.7 \%$ & $35.7 \%$ & $20.0 \%$ & $0.012^{\mathrm{a}, \mathrm{b}}$ \\
\hline Hypertensive & $59.9 \%$ & $73.0 \%$ & $56.3 \%$ & $49.5 \%$ & $0.01^{a, c}$ \\
\hline Diabetic & $23.2 \%$ & $25.2 \%$ & $16.1 \%$ & $28.6 \%$ & 0.06 \\
\hline Hypercholesterolemia & $55.7 \%$ & $65.2 \%$ & $56.3 \%$ & $44.8 \%$ & $0.01^{c}$ \\
\hline Physically inactive* & $54.5 \%$ & $68.7 \%$ & $46.4 \%$ & $47.6 \%$ & $0.001^{a, c}$ \\
\hline
\end{tabular}

${ }^{*}<3$ times/week; angina vs. MI; ${ }^{\text {HF }}$ vs. MI; 'HF vs. angina; HADS — Hospital Anxiety and Depression Scale

group $(\mathrm{n}=31)$ and each diagnosis even though the sample sizes were small (angina, and MI, $\mathrm{n}=12$ each; HF, $\mathrm{n}=7$ ).

\section{MacNew exploratory factor analysis (Table 4)}

The original 3-factor structure for the Polish version was largely confirmed (with loadings $\geq 0.40$ ) explaining $53.5 \%$ of the variance (emotional subscale, $21.7 \%$; physical subscale, $19.7 \%$; social subscale, $12.1 \%$ ). Eight items partially conformed to the original factor structure; 2 of the 14 emotional subscale items, 1 of the 13 the physical subscale items, and 5 of the 14 social subscale items.

\section{MacNew convergent validity (Table 5)}

The $a$ priori convergent hypotheses for strong correlations, i.e., $r \geq 0.50$, between corresponding MacNew and SF-36 constructs and lower correlations between dissimilar constructs were confirmed.
All correlations between the corresponding MacNew and SF-36 constructs, i.e., MacNew physical subscale and SF-36 PCS, MacNew emotional subscale and SF-36 MCS, were both strong and significant. The correlations between dissimilar MacNew and SF-36 constructs, although $\geq 0.50$ on the emotional subscale in the total group and in patients with MI, were significantly lower than for the similar constructs.

\section{MacNew discriminative validity (Table 6)}

Using the SF-36 health transition item, MacNew scores in patients with angina, MI, or HF whose health either improved or stayed the same were not significantly different and so the data from the two groups were combined. Patients in the total group and patients with HF whose health either improved or stayed the same had higher MacNew scores on the global scale and each subscale when compared to patients whose 
Table 2. Mean MacNew, SF36 physical component scale (PCS) and mental component scale (MCS) and Hospital and Anxiety Scale (HADS) scores \pm standard deviation in the total group and by diagnosis (stable coronary artery disease with angina [angina], myocardial infarction [MI] and heart failure [HF]).

\begin{tabular}{llccccc}
\hline & & Total group & Angina & MI & HF & P \\
\hline MacNew & Global & $4.8 \pm 1.0$ & $4.6 \pm 0.8$ & $5.3 \pm 0.9$ & $4.6 \pm 1.0$ & $<0.001^{\mathrm{a}, \mathrm{b}}$ \\
& Physical & $4.5 \pm 1.2$ & $4.3 \pm 0.9$ & $5.1 \pm 1.1$ & $4.1 \pm 1.2$ & $<0.001^{\mathrm{a}, \mathrm{b}}$ \\
& Emotional & $5.0 \pm 1.0$ & $4.8 \pm 0.9$ & $5.4 \pm 1.0$ & $4.9 \pm 1.0$ & $<0.001^{\mathrm{a}, \mathrm{b}}$ \\
& Social & $4.9 \pm 1.1$ & $4.8 \pm 1.0$ & $5.4 \pm 1.1$ & $4.6 \pm 1.1$ & $<0.001^{\mathrm{a}, \mathrm{b}}$ \\
SF-36 & PCS & $375 \pm 10.3$ & $35.2 \pm 8.5$ & $42.7 \pm 9.8$ & $34.3 \pm 10.4$ & $<0.001^{\mathrm{a}, \mathrm{b}}$ \\
& MCS & $45.8 \pm 10.0$ & $451 \pm 10.6$ & $47.8 \pm 9.0$ & $458 \pm 10.3$ & 0.45 \\
HADS & Anxiety & $7.4 \pm 3.7$ & $8.0 \pm 3.6$ & $6.8 \pm 3.5$ & $7.2 \pm 4.1$ & $<0.05^{\mathrm{a}}$ \\
& Depression & $6.1 \pm 3.6$ & $6.2 \pm 3.5$ & $5.3 \pm 3.5$ & $6.8 \pm 3.7$ & $<0.01^{\mathrm{b}}$ \\
\hline
\end{tabular}

${ }^{\mathrm{a}} \mathrm{MI}$ vs. angina; ${ }^{\mathrm{b}} \mathrm{MI}$ vs. HF

Table 3. MacNew global and subscale floor and ceiling effects, internal consistency (Cronbach's $\alpha$ ) and test-retest reliability $(n=126)$ in the total group and by diagnosis (stable coronary artery disease with angina, myocardial infarction [MI] and heart failure [HF]).

\begin{tabular}{|c|c|c|c|c|}
\hline & \multicolumn{4}{|c|}{ MacNew } \\
\hline & Global & Physical & Emotional & Social \\
\hline \multicolumn{5}{|l|}{ Total group } \\
\hline$\%$ Floor & $0 \%$ & $0 \%$ & $0 \%$ & $0 \%$ \\
\hline$\%$ Ceiling & $0 \%$ & $0.6 \%$ & $0.3 \%$ & $1.2 \%$ \\
\hline Cronbach's $\alpha$ & 0.94 & 0.91 & 0.91 & 0.90 \\
\hline$r_{t t}(n=31)$ & $0.98^{*}$ & $0.98^{*}$ & $0.98^{*}$ & $0.98^{*}$ \\
\hline \multicolumn{5}{|l|}{ Angina } \\
\hline$\%$ Floor & $0 \%$ & $0 \%$ & $0 \%$ & $0 \%$ \\
\hline$\%$ Ceiling & $0 \%$ & $0 \%$ & $0 \%$ & $0 \%$ \\
\hline Cronbach's $\alpha$ & 0.93 & 0.86 & 0.91 & 0.89 \\
\hline$r_{t t}(n=12)$ & $0.99^{*}$ & $0.98^{*}$ & $0.99^{*}$ & $0.99^{*}$ \\
\hline \multicolumn{5}{|l|}{ MI } \\
\hline$\%$ Floor & $0 \%$ & $0 \%$ & $0 \%$ & $0 \%$ \\
\hline$\%$ Ceiling & $0 \%$ & $1.8 \%$ & $0 \%$ & $1.8 \%$ \\
\hline Cronbach's $\alpha$ & 0.92 & 0.89 & 0.92 & 0.90 \\
\hline$r_{t t}(n=12)$ & $0.96^{*}$ & $0.94^{*}$ & $0.97^{*}$ & $0.95^{*}$ \\
\hline \multicolumn{5}{|l|}{$\mathrm{HF}$} \\
\hline$\%$ Floor & $0 \%$ & $0 \%$ & $0 \%$ & $0 \%$ \\
\hline$\%$ Ceiling & $0 \%$ & $0 \%$ & $1 \%$ & $1.9 \%$ \\
\hline Cronbach's $\alpha$ & 0.95 & 0.92 & 0.91 & 0.89 \\
\hline$r_{t t}(n=7)$ & $0.98^{*}$ & $0.97 *$ & $0.97^{*}$ & $0.98^{*}$ \\
\hline
\end{tabular}

${ }^{*} p<0.01$

health had deteriorated $(\mathrm{p}<0.001)$. Patients with angina whose health either improved or stayed the same had higher MacNew scores only on the social subscale when compared to patients whose health had deteriorated $(\mathrm{p}=0.03)$. Patients with MI whose health either improved or stayed the same had higher MacNew scores on the physical subscale $(\mathrm{p}<0.001)$ and on the global scale and the social subscale $(\mathrm{p}=0.01)$ than patients whose health had deteriorated. With both HADS anxiety and depression, patients in the total group and each diagnosis without anxiety or depression symptoms 
Table 4. Principal component analysis: factor loadings $\geq 0.40$ for each MacNew item in the total group. Loadings $<0.40$ are not displayed and items with asterisk $\left({ }^{*}\right)$ do not conform fully to the original factor analysis.

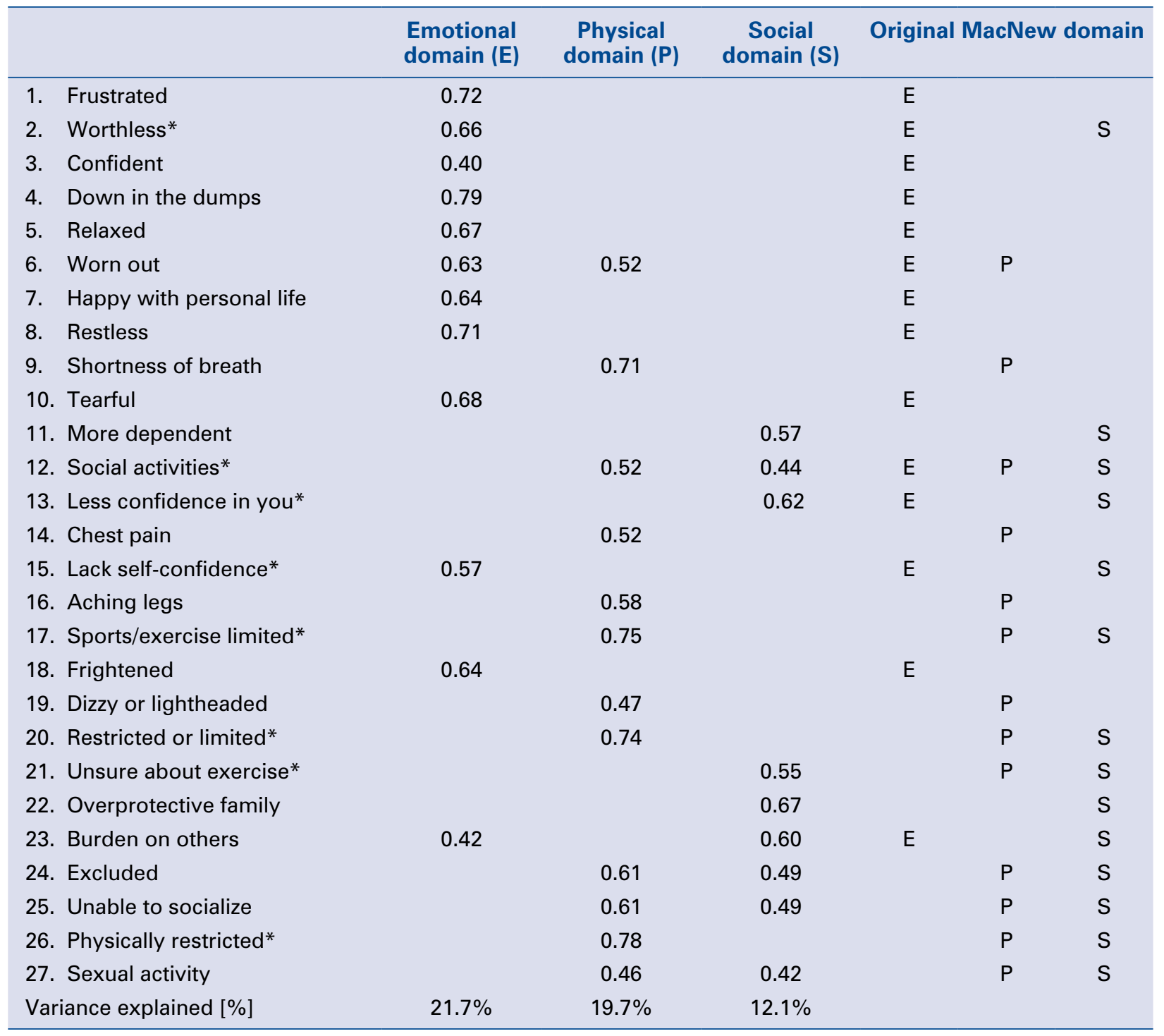

had higher MacNew scores on the global scale and each subscale than patients with symptoms $(\mathrm{p}<0.001)$.

\section{Discussion}

The Polish version of the MacNew in 332 patients with angina, MI, or HF demonstrated satisfactory psychometric properties. The original 3 -factor structure for the Polish version was largely confirmed. Internal consistency reliability was always $\geq 0.86$ and test-retest reliability always significant and $\geq 0.94$ in the total group and each diagnosis. All correlations between the corresponding MacNew and SF-36 constructs were both strong and significant with significantly lower correlations between dissimilar constructs. Discriminative validity was fully demonstrated on the SF-36 health transition item in the total group and in patients with HF although only partially confirmed in patients with either angina or MI. Discriminative validity was also fully demonstrated with both HADS anxiety and depression. In addition, the MacNew is well rated by patients as being user-friendly with the instructions easy to follow, the questions understandable and relevant to patients' problems and is completed in approximately $10 \mathrm{~min}$. Consistent with other language reports on the MacNew [22-25], the Polish MacNew can be considered a potential CAD-specific core HRQL questionnaire allowing across-diagnosis comparisons with one HRQL questionnaire. 
Table 5. Convergent validity of the MacNew physical and emotional subscales with the Short Form-36 physical component scale (PCS) and mental component scale (MCS) in the total group and by diagnosis; strong correlations bolded.

\begin{tabular}{|c|c|c|c|}
\hline & MacNew physical subscale & MacNew emotional subscale & $P(1 \text {-sided })^{*}$ \\
\hline \multicolumn{4}{|c|}{ Total group $(\mathrm{n}=332)$ : } \\
\hline SF-36 PCS & 0.72 & 0.50 & $<0.001$ \\
\hline SF-36 MCS & 0.43 & 0.71 & $<0.001$ \\
\hline $\mathrm{P}(1 \text {-sided })^{*}$ & $<0.001$ & $<0.001$ & \\
\hline \multicolumn{4}{|l|}{ Angina $(n=115)$ : } \\
\hline SF-36 PCS & 0.63 & 0.36 & $<0.001$ \\
\hline SF-36 MCS & 0.47 & 0.73 & $<0.001$ \\
\hline$P(1 \text {-sided })^{*}$ & $<0.05$ & $<0.001$ & \\
\hline \multicolumn{4}{|c|}{ Myocardial infarction ( $n=112$ ): } \\
\hline SF-36 PCS & 0.77 & 0.51 & $<0.001$ \\
\hline SF-36 MCS & 0.45 & 0.71 & $<0.01$ \\
\hline $\mathrm{P}(1 \text {-sided })^{*}$ & $<0.001$ & $<0.001$ & \\
\hline \multicolumn{4}{|c|}{ Heart failure $(n=105)$ : } \\
\hline SF-36 PCS & 0.72 & 0.49 & $<0.001$ \\
\hline SF-36 MCS & 0.42 & 0.71 & $<0.001$ \\
\hline $\mathrm{P}(1 \text {-sided })^{*}$ & $<0.001$ & $<0.01$ & \\
\hline
\end{tabular}

*Steiger's test for comparing Pearson correlation coefficients; P-values for all correlations $<0.001$

Consistent with MacNew publications in other languages, patients with MI had significantly better HRQL than patients with either angina or HF [24-26]. Also consistent with other MacNew publications, there were no MacNew floor effects and ceiling effects were observed in $<2.0 \%$ of all patients $[24,25]$. With floor and ceiling effects of $1 \%$ to $15 \%$ considered small [27], the MacNew clearly is responsive both to HRQL deterioration and improvement in each diagnostic group.

The statistical analysis of the Polish version of MacNew was carried out according to the international criteria and recommended procedure for psychometric analysis [19]. Factor analysis explained $53.5 \%$ of the total variance which is similar to results obtained in other languages versions of MacNew in a sample of patients with angina, MI and HF [26, 28-30]. Nineteen of the $27 \mathrm{MacNew}$ items $(70 \%)$ loaded consistently with the original MacNew 3-factor structure [6]. The emotional subscale, with one item, and the physical subscale, with 2 items, loaded most consistently with the original 3-factor structure. However, 5 of the social subscale items did not load with the original structure of the social scale which is consistent with similar proportions in other languages, e.g., German [14, 30, 31] and Portuguese [29]. The sexual activity item (\#27) falls into the physical and social subscales in this report; however, this item was not included in the original factor analysis and has recently been shown to fall into the social rather than the physical subscale $[22,29]$. The original factor structure of the MacNew allowed items with loadings of $\geq 0.40$ to load on more than one subscale which is of concern $[32,33]$ and is being investigated with other analytic approaches.

The Polish MacNew demonstrated good internal consistency reliability with Cronbach's $\alpha$ always $\geq 0.86$ with test-retest reliability always $\geq 0.94$ for the global scale and each subscale in the total group and each diagnosis. There is relatively consistent evidence for Polish MacNew's construct validity with convergent validity confirmed in part with strong correlations as predicted between similar MacNew and SF-36 constructs. However, some of the correlations between dissimilar constructs (e.g., MacNew physical and SF-36 MCS scales) were higher than expected which has also been observed in previous studies [25, 29]. This may be related to the way the MacNew probes were originally developed with the focus on the patient's perceptions of the difficulties with physical activities rather than on physical performance as in the SF-36 [29].

As there were no significant differences between the "improved health" and "stayed the same 
Table 6. Discriminant validity of MacNew global score and subscale scores (mean \pm standard deviation) by SF-36 health status transition and Hospital Anxiety and Depression Scale (HADS) anxiety and depression in the total group and by diagnosis (stable coronary artery disease with angina (angina), myocardial infarction and [Ml] heart failure [HF]).

\begin{tabular}{|c|c|c|c|c|}
\hline & \multicolumn{4}{|c|}{ MacNew } \\
\hline & Global & Physical & Emotional & Social \\
\hline \multicolumn{5}{|l|}{ Total group } \\
\hline \multicolumn{5}{|l|}{ SF-36 health transition: } \\
\hline Improve/no change & $5.2 \pm 0.9$ & $5.0 \pm 1.2$ & $5.4 \pm 0.8$ & $5.4 \pm 1.0$ \\
\hline Deteriorate & $4.6 \pm 1.0$ & $4.2 \pm 1.1$ & $4.9 \pm 1.1$ & $4.7 \pm 1.1$ \\
\hline $\mathrm{P}$ & $<0.001$ & $<0.001$ & $<0.001$ & $<0.001$ \\
\hline \multicolumn{5}{|l|}{ Anxiety: } \\
\hline No & $5.2 \pm 0.8$ & $4.8 \pm 1.1$ & $5.5 \pm 0.7$ & $5.2 \pm 1.0$ \\
\hline Yes & $4.3 \pm 1.0$ & $4.1 \pm 1.1$ & $4.5 \pm 1.0$ & $4.5 \pm 1.1$ \\
\hline $\mathrm{P}$ & $<0.001$ & $<0.001$ & $<0.001$ & $<0.001$ \\
\hline \multicolumn{5}{|l|}{ Depression: } \\
\hline No & $5.1 \pm 0.8$ & $4.8 \pm 1.1$ & $5.4 \pm 0.8$ & $5.2 \pm 1.0$ \\
\hline Yes & $4.1 \pm 0.9$ & $3.9 \pm 1.1$ & $4.3 \pm 1.0$ & $4.2 \pm 1.1$ \\
\hline $\mathrm{P}$ & $<0.001$ & $<0.001$ & $<0.001$ & $<0.001$ \\
\hline \multicolumn{5}{|l|}{ Angina } \\
\hline \multicolumn{5}{|l|}{ SF-36 health transition: } \\
\hline Improve/no change & $4.9 \pm 0.8$ & $4.5 \pm 1.1$ & $5.1 \pm 0.8$ & $5.1 \pm 0.9$ \\
\hline Deteriorate & $4.5 \pm 0.9$ & $4.2 \pm 0.9$ & $4.7 \pm 0.9$ & $4.6 \pm 1.0$ \\
\hline$P$ & 0.06 & 0.09 & 0.06 & 0.03 \\
\hline \multicolumn{5}{|l|}{ Anxiety: } \\
\hline No & $5.1 \pm 0.7$ & $4.7 \pm 0.9$ & $5.4 \pm 0.7$ & $5.2 \pm 0.8$ \\
\hline Yes & $4.2 \pm 0.8$ & $4.0 \pm 0.8$ & $4.3 \pm 0.8$ & $4.4 \pm 0.9$ \\
\hline$P$ & $<0.001$ & $<0.001$ & $<0.001$ & $<0.001$ \\
\hline \multicolumn{5}{|l|}{ Depression: } \\
\hline No & $4.9 \pm 0.7$ & $4.6 \pm 0.9$ & $5.2 \pm 0.8$ & $5.1 \pm 0.8$ \\
\hline Yes & $4.0 \pm 0.8$ & $3.8 \pm 0.9$ & $4.1 \pm 0.8$ & $4.2 \pm 0.9$ \\
\hline$P$ & $<0.001$ & $<0.001$ & $<0.001$ & $<0.001$ \\
\hline \multicolumn{5}{|l|}{ Myocardial infarction } \\
\hline \multicolumn{5}{|l|}{ SF-36 health transition: } \\
\hline Improve/no change & $5.6 \pm 0.8$ & $5.7 \pm 1.0$ & $5.6 \pm 0.8$ & $5.8 \pm 0.9$ \\
\hline Deteriorate & $5.0 \pm 1.0$ & $4.8 \pm 1.1$ & $5.2 \pm 1.0$ & $5.1 \pm 1.1$ \\
\hline $\mathrm{P}$ & 0.01 & $<0.001$ & 0.2 & 0.01 \\
\hline \multicolumn{5}{|l|}{ Anxiety: } \\
\hline No & $5.6 \pm 0.7$ & $5.4 \pm 1.0$ & $5.7 \pm 0.7$ & $5.6 \pm 0.9$ \\
\hline Yes & $4.9 \pm 1.1$ & $4.7 \pm 1.2$ & $4.9 \pm 1.1$ & $5.0 \pm 1.2$ \\
\hline$P$ & $<0.001$ & $<0.001$ & $<0.001$ & $<0.01$ \\
\hline \multicolumn{5}{|l|}{ Depression: } \\
\hline No & $4.9 \pm 1.0$ & $4.4 \pm 1.3$ & $5.3 \pm 0.9$ & $5.0 \pm 1.1$ \\
\hline Yes & $4.0 \pm 0.9$ & $3.6 \pm 0.9$ & $4.3 \pm 1.0$ & $4.0 \pm 1.0$ \\
\hline $\mathrm{P}$ & $<0.001$ & $<0.001$ & $<0.001$ & $<0.001$ \\
\hline \multicolumn{5}{|l|}{ Heart failure } \\
\hline \multicolumn{5}{|l|}{ SF-36 health transition: } \\
\hline Improve/no change & $5.1 \pm 0.9$ & $4.7 \pm 1.2$ & $5.4 \pm 0.8$ & $5.2 \pm 1.0$ \\
\hline Deteriorate & $4.2 \pm 1.0$ & $3.7 \pm 1.0$ & $4.6 \pm 1.1$ & $4.2 \pm 1.1$ \\
\hline$P$ & $<0.001$ & $<0.001$ & $<0.001$ & $<0.001$ \\
\hline \multicolumn{5}{|l|}{ Anxiety: } \\
\hline No & $4.9 \pm 0.9$ & $4.3 \pm 1.3$ & $5.3 \pm 0.8$ & $4.9 \pm 1.1$ \\
\hline Yes & $4.1 \pm 1.0$ & $3.7 \pm 1.0$ & $4.3 \pm 1.0$ & $4.2 \pm 1.1$ \\
\hline$P$ & $<0.001$ & $<0.01$ & $<0.001$ & $<0.01$ \\
\hline \multicolumn{5}{|l|}{ Depression: } \\
\hline No & $4.9 \pm 1.0$ & $4.4 \pm 1.3$ & $5.3 \pm 0.9$ & $5.0 \pm 1.1$ \\
\hline Yes & $4.0 \pm 0.9$ & $3.6 \pm 0.9$ & $4.3 \pm 1.0$ & $4.0 \pm 1.0$ \\
\hline $\mathrm{P}$ & $<0.001$ & $<0.001$ & $<0.001$ & $<0.001$ \\
\hline
\end{tabular}


health" groups, we combined the two groups and compared the MacNew scores for the combined group and the deteriorated health group. Discriminative validity was fully demonstrated with significantly lower HRQL scores in the total group and in patients with HF, largely confirmed in patients with MI, but only partially confirmed in patients with angina when compared to those whose health improved or stayed the same. From a clinical rather than statistical perspective, the minimal important difference (MID) on the MacNew is 0.5 points [34]. Norman et al. [35] have suggested that "in most circumstances, the threshold of discrimination for changes in health-related quality of life for chronic diseases appears to be approximately half a standard deviation". The standard deviation of the baseline global MacNew score in the total cohort is 1.0 in the present study which supports the earlier observation of an MID of 0.5 points on the MacNew [34]. All MacNew score differences between those whose health had deteriorated and those who improved or stayed the same met or exceeded the MID in the total group and in patients with HF; in patients with MI, the MID was met or exceeded on the global scale and the physical and social subscales; in patients with MI, the MID was met only on the social subscale. Discriminative validity was fully confirmed with HADS anxiety and depression symptoms in the total group and in each diagnosis and patients without HADS anxiety and depression symptoms had significantly better HRQL than patients with HADS anxiety and depression.

As the parent HeartQoL Project was an international cross-sectional survey of HRQL [9], demonstration of the responsiveness in the Polish MacNew was not possible. This needs to be investigated in a prospective study in Polish patients with CAD before a full recommendation of the Polish MacNew as a core CAD-specific HRQL questionnaire can be made.

\section{Conclusions}

The Polish version of the MacNew HRQL questionnaire appears to be both reliable and valid, demonstrating satisfactory psychometric properties in this Polish sample of patients with CAD. The Polish MacNew can be recommended for assessing and evaluating HRQL for patients suffering from angina or $\mathrm{HF}$ and following $\mathrm{MI}$ in clinical studies.

Conflict of interest: None declared

\section{References}

1. Geigle R, Jones SB. Outcomes measurement: A report from the front. Inquiry, 1990; 27: 7-13.

2. Leplége A, Hunt $\mathrm{S}$. The problem of quality of life in medicine. JAMA, 1997; 278: 47-50.

3. Cepeda-Valery B, Cheong AP, Lee A, Yan BP. Measuring health related quality of life in coronary heart disease: The importance of feeling well. Int J Cardiol, 2011; 149: 4-9.

4. Anker SD, Agewall S, Borggrefe M et al. The importance of patientreported outcomes: A call for their comprehensive integration in cardiovascular clinical trials. Eur Heart J, 2014; 35: 2001-2009.

5. Spertus JA. Evolving applications for patient-centered health status measures. Circulation, 2008; 118: 2103-2110.

6. Valenti L, Lim L, Heller RF, Knapp J. An improved questionnaire for assessing quality of life after acute myocardial infarction. Qual Life Res, 1996; 5: 151-161.

7. Rector TS, Cohn JN. Assessment of patient outcome with the Minnesota Living with Heart Failure questionnaire: Reliability and validity during a randomized, double-blind, placebo-controlled trial of pimobendan. Pimobendan Multicenter Research Group. Am Heart J, 1992; 124: 1017-1025.

8. Thompson DR, Yu CM. Quality of life in patients with coronary heart disease-I: Assessment tools. Health Qual Life Outcomes, 2003; 1 : 42-49.

9. Oldridge N, Hofer S, McGee H, Conroy R, Doyle F, Saner H. The HeartQoL: Part I. Development of a new core health-related quality of life questionnaire for patients with ischemic heart disease. Eur J Prev Cardiol, 2014; 21: 90-97.

10. Bullinger M, Alonso J, Apolone G et al. Translating health status questionnaires and evaluating their quality: The IQOLA Project approach. International Quality of Life Assessment. J Clin Epidemiol, 1998; 51: 913-923.

11. MacNew, o. MacNew health-related quality of life instrument. Available from: http://www macnew org/wp/; 2013.

12. Ware JE, Jr. SF-36 health survey update. Spine (Phila Pa 1976 ), 2000; 25: 3130-3139.

13. Zigmond AS, Snaith RP. The hospital anxiety and depression scale. Acta Psychiatr Scand, 1983; 67: 361-370.

14. Höfer S, Lim L, Guyatt G, Oldridge N. The MacNew Heart Disease health-related quality of life instrument: A summary. Health Qual Life Outcomes, 2004; 2: 3-9.

15. Tobiasz-Adamczyk B. Geneza zdrowia, koncepcje i ewolucja pojęcia jakości życia. In: Kawecka-Jaszcz K, Klocek J, TobuaszAdamczyk B eds. Jakość życia w chorobach układu sercowonaczyniowego. Metody pomiaru i znaczenie kliniczne. Termedia, Poznań 2006.

16. Bjelland I, Dahl AA, Haug TT, Neckelmann D. The validity of the Hospital Anxiety and Depression Scale. An updated literature review. J Psychosom Res, 2002; 52: 69-77.

17. Majkowicz M. Praktyczna ocena efektywności opieki paliatywnej: Wybrane techniki badawcze. In: de Walden-Gałuszko K, Majkowicz M eds. Ocena jakości opieki paliatywnej w teorii i praktyce. Wydawnictwo Akademii Medycznej w Gdańsku, Gdańsk 2000.

18. Hays RD, Anderson RT, Revicki D. Assessing reliability and validity of measurement in clinical trials. In: Staquet MJ, Hays RD, Fayers P eds. Quality of life assessment in clinical trials: Methods and practice. Oxford University Press, New York 1998, 169-182. 
19. Scientific Advisory Committee of Medical Outcomes Trust. Assessing health status and quality-of life instruments: Attributes and review criteria. Quality of Life Res, 2002; 11: 193-205.

20. Cohen J. Statistical Power Analysis for the Behavioral Sciences. Routledge; 2 Ed. 1988.

21. Steiger JH. Tests for comparing elements of a correlation matrix. Psychol Bull, 1980; 87: 245-251.

22. De Gucht V, van Elderen T, van der Kamp L, Oldridge N. Quality of life after myocardial infarction: translation and validation of the MacNew Questionnaire for a Dutch population. Qual Life Res, 2004; 13: 1483-1488.

23. Yu DS, Thompson DR, Yu CM, Oldridge NB. Validation of the Chinese version of the MacNew heart disease health-related quality of life questionnaire. J Eval Clin Pract, 2008; 14: 326-335.

24. Höfer S, Saleem A, Stone J, Thomas R, Tulloch H, Oldridge N. The MacNew Heart Disease Health-Related Quality of Life Questionnaire in patients with angina and patients with ischemic heart failure. Value Health, 2012; 15: 143-150.

25. Vandereyt F, Dendale P, Vanhees L, Roosen J, Hofer S, Oldridge N. Psychometric properties of the Flemish version of the MacNew heart disease health-related quality of life questionnaire. Acta Cardiol, 2012; 67: 31-39.

26. Alphin S, Hofer S, Perk J, Slordahl S, Olsen Zwisler AD, Oldridge N. The MacNew Heart Disease Health-Related Quality of Life Questionnaire: A Scandinavian Validation Study. Soc Indic Res, 2014; doi: 10.1007/s11205-014-0694-7.

27. McHorney CA,Tarlov AR. Individual-patient monitoring in clinical practice: Are available health status surveys adequate? Qual Life Res, 1995; 4: 293-307.
28. Hiller A, Helvik AS, Kaasa S, Slordahl SA. Psychometric properties of the Norwegian MacNew Heart Disease health-related quality of life inventory. Eur J Cardiovasc Nurs, 2010; 9: 146-152.

29. Leal A, Paiva C, Hofer S, Amado J, Gomes L, Oldridge N. Evaluative and discriminative properties of the Portuguese MacNew Heart Disease Health-related Quality of Life Questionnaire. Qual Life Res, 2005; 14: 2335-2341.

30. Höfer S, Schmid JP, Frick M et al. Psychometric properties of the MacNew heart disease health-related quality of life instrument in patients with heart failure. J Eval Clin Pract, 2008; 14: 500-506.

31. Gramm L, Farin E, Jaeckel WH. Psychometric properties of the German version of the MacNew heart disease health-related quality of life questionnaire. Health Qual Life Outcomes, 2012; 10: 83-91.

32. Dempster M, Donnelly M, O'Loughlin C. The validity of the MacNew Quality of Life in heart disease questionnaire. Health Qual Life Outcomes, 2004; 2: 6-9.

33. Ribera A, Permanyer-Miralda G, Alonso J, Cascant P, Soriano N, Brotons C. Is psychometric scoring of the McNew Quality of Life after Myocardial Infarction questionnaire superior to the clinimetric scoring? A comparison of the two approaches. Qual Life Res, 2006; 15: 357-365.

34. Dixon T, Lim LL, Oldridge NB. The MacNew heart disease health-related quality of life instrument: reference data for users. Qual Life Res, 2002; 11: 173-183.

35. Norman GR, Sloan JA, Wyrwich KW. The truly remarkable universality of half a standard deviation: Confirmation through another look. Expert Rev Pharmacoecon Outcomes Res, 2004; 4: 581-585. 